\title{
Cultura de paz, pensar y repensar. Una respuesta al golpe
}

\section{Culture of peace, think and rethink. A response to the coup}

\author{
Xavier Ernesto Rodríguez Corea \\ Departamento de Antropología \\ Universidad Nacional Autónoma de Nicaragua, Managua \\ ID Orcid: https://orcid.org/0000-0002-2335-2477 \\ xerco505@gmail.com
}

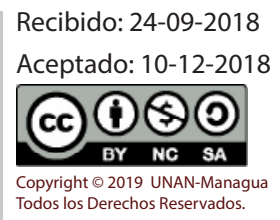

\section{Resumen}

La cultura de Paz, más que un concepto es una filosofía, una forma de ver el mundo y al otro, ¿cómo concretamos esa visión en la vida cotidiana? , la cultura de paz puede ser entendida desde diversas posibilidades y por consiguiente se aplicaría a la vida misma de diversas formas. En este ensayo se busca reflexionar sobre este concepto, vital para Nicaragua luego del intento de golpe de estado fracasado y la necesidad de rematar cualquier asomo de fascismo, cada vez más popular entre algunos sectores como reacción al avance de los sectores populares en la patria grande. En un primer momento queremos abordar el contexto del golpe de estado en Nicaragua, luego reflexionar a modo de paréntesis, algunos elementos sobre la relación al devenir histórico del concepto de paz en diversas culturas y tiempos; finalmente regresar a Nicaragua a plantear algunos elementos de esta cultura de paz muy nuestra que estamos construyendo. Finalmente es importante dejar sentado que el escrito esta pensado desde la postura del intelectual orgánico (Gramsci) y huye de la posibilidad de analizar de forma neutral, muy de moda entre algunos académicos.

Palabras claves: Cultura de paz, Antropología, Golpe suave, Relaciones de conflicto

\section{Abstract}

The culture of Peace, more than a concept is a philosophy, a way of seeing the world and the other, how do we realize that vision in everyday life?, the culture of peace can be understood from various possibilities and therefore would be applied to life itself in different ways. This essay seeks to reflect on this concept, vital for Nicaragua after the failed coup attempt and the need to finish off any hint of fascism, increasingly popular among some sectors as a reaction to the advancement of popular sectors in the homeland.. At first we want to address the context of the coup d'etat in Nicaragua, then reflect in parentheses, some elements on the relationship to the historical evolution of the concept of peace in different cultures and times; Finally, return to Nicaragua to raise some elements of this culture of peace that we are building. Finally it is important to make it clear that the writing is thought from the posture of the organic intellectual (Gramsci) and runs away from the possibility of analyzing neutrally, very fashionable among some academics.

Keywords: Culture of peace, Anthropology, Soft coup, Conflict relations 


\section{Introducción: Los antecedentes del in- tento de golpe}

Luego de la derrota electoral del FSLN en el año 1990 y la llegada al poder de los gobiernos de derecha, los partidos políticos que gobernaban y algunas ONGs que se movían delante y detrás de bambalinas, sumergieron a la población más empobrecida en situaciones de precariedad extrema, mientras se aplican las recetas del FMI y el banco Mundial al pie de letra. Eran esos años donde el presupuesto de la república era elaborado por técnicos de Washington, mientras la necesidad de la población era dejada en la mano del dios mercado, y la pobreza era endulzada con proyectos ejecutados con fondos de la cooperación internacional por las ONGs que habían desmenuzado y privatizado los derechos humanos.

\begin{abstract}
"Una vez que recuperaron el gobierno, la restauración y la contrarrevolución desmantelaron el incipiente bienestar social alcanzado por las políticas revolucionarias, especialmente en materia de educación, salud, alimentos y vivienda. Durante el período que duró la restauración, las principales fuerzas sociales, particularmente la clase trabajadora, fue lanzada a la desocupación en un rápido proceso de "desmercantilización" laboral y de reprivatización de los bienes que habían sido nacionalizados, no solamente por el régimen sandinista, sino por la propia dictadura somocista" (Soto, 2015, pág. 307)
\end{abstract}

Luego de tres gobiernos neoliberales, el FSLN llega al gobierno con el voto popular y se afianza allí por varias elecciones donde se consolido el respaldo de los votantes a nivel nacional y municipal, cada elección fue sucedida por el desarrollo de programas y proyectos de restitución de derechos, que atendían las necesidades básicas de la población, techo, alimentación, producción, educación, salud. resultado de las políticas de estado durante los últimos años Nicaragua se perfila como uno de los países más seguros de la región, crímenes que son comunes en los países vecinos como secuestros, asesinatos atroces, establecimiento de grupos armados y narcotraficantes en el territorio, en Nicaragua eran inexistentes o no se presentaban con la magnitud de los países vecinos. Además, de la seguridad ciudadana, los indicadores económicos como reducción de la pobreza, pobreza extrema, empleo e inversión pública, los indicadores positivos que muchos personeros de la derecha ni se atreven a discutir y se limitan a diluir con argumentos como "es deber del gobierno".

Los argumentos de los políticos opositores al gobierno sandinista son escuetos cuando intentan no recordar que durante muchos años en Nicaragua las medidas neoliberales como privatizaciones y recortes a programas sociales fueron aplaudidos y rubricados por la "sociedad civil" que en el país puede, aunque no debería, entenderse como un grupo elite de ONG's que en nombre de toda una sociedad respaldaban estas políticas a cambio de mega salarios o dietas. Muchas de estas ONGs y grupos de elites intelectuales y económicos hoy se autodenominan "auto-convocados" en oposición al gobierno sandinista, unos surgidos de la disidencia y la traición al el sandinismo en los años 90 , otros surgidos de la contrarrevolución somocista de los años 80 y otros surgidos de mundo de las ONGs, la elite media-alta; pequeños grupos de clase media y desclasados surgidos en los últimos 12 años desde que FSLN retorno al gobierno, incluyendo los intelectuales conversos posmodernos que empezaron a reaccionar a las políticas sociales que socializaban lo que antes era exclusivo de ellos.

\section{El golpe}

Durante los últimos años en los países de este continente -y de otros- donde los gobiernos no eran adeptos a las políticas interventoras de Estados Unidos se han evidenciado una nueva modalidad de golpe, distinta a los golpes de gorilas de la operación cóndor , la modalidad donde surgían aparentes movilizaciones espontáneas, operaciones de falsas banderas y el uso de redes sociales, iniciaban y justificaba el cambio de gobierno, hacia llamadas "transiciones democráticas" o en otra palabras, gobiernos al servicio del mandato norteamericano. Muchos de los episodios que vivimos en Nicaragua son muy parecidos a los vividos en Venezuela, uso de las redes sociales para convertir mentiras absurdas, en verdades absolutas, la exacerbación de una parte de la población por medio de la manipulación emocional hasta llevarla al fascismo, el financiamiento 
norteamericano a grupos de oposición, el linchamiento a los sectores políticos nacionalistas por una maquinaria comunicacional manejada desde Estados unidos y Europa y el doble discurso democrático-violento de grupos nacionales que aspiran a controlar el poder gubernamental.

Un joven desnudado, golpeado, humillado, pintado, por parecer sandinista, un hombre mayor asesinado y quemado su cuerpo en las calles de Managua, un mujer torturada y violada, luego de asesinar a su compañero de vida delante suyo, ancianos, golpeados, desnudados, grabados y publicados, edificios públicos saqueados e incendiados, entre estos las universidades públicas, son solo algunos de los cientos de episodios de crímenes de odios y delincuencia que vivió Nicaragua, episodios aun desconocidos por muchos, debido al cerco mediático o la ceguera intencionada, principalmente por algunos pocos en el mundo académico que aún siguen hablando de un "revuelta pacífica".

\section{Para la cultura de paz: la paz es una cuestión de culturas}

Según las Naciones Unidas en el documento titulado "hacia una cultura de paz" enuncia que:

El concepto de una cultura de paz surgió del Congreso Internacional sobre "La Paz en la Mente de los Hombres", que la Organización de las Naciones Unidas para la Educación, la Ciencia y la Cultura (UNESCO) organizó en Côte d'Ivoire en julio de 1989. Desde entonces se ha considerado que la promoción de una cultura de paz es un objetivo que cada vez adquiere mayor trascendencia para la comunidad internacional. La evolución del concepto ha inspirado la realización de actividades en muy diversos niveles y en muchas regiones con la plena participación de la sociedad civil, con lo cual la cultura de paz está adquiriendo paulatinamente las características de un movimiento mundial (Organización de las Naciones Unidas, 1997)

Aun hoy en día hay varias posibilidades de como entendemos y asumimos la cultura de paz, tal vez y solo tal vez, podría ser bueno hacer un recorrido por las distintas definiciones y visiones de paz en la historia de la humanidad, solo algunos ejemplos de los muchos contextos culturales, espaciales y humanos podría ayudar a deslumbrar esta diversidad en el tiempo y en espacio y la riqueza que concepciones que nos puede ayudar a entender la forma en que entendemos hoy.

La sociedad romana es el prototipo de imperio, armamentista, expansionista - invasor y saqueador, la Pax Romana o Pax Augusta es el prototipo de paz impuesta por una maquinaria bélica y el exterminio militar, político- cultural , para el primero se cuenta con un ejército de primer nivel y para lo segundo con una maquinaria política que permite la imposición de valores y lógicas culturales etnocéntricas, que proponen la cultura propia como parámetro que mide a las demás y que impone por la fuerza o sutilmente sus lógicas y cosmovisiones, para esto usa el derecho que nos llega como principio básico del derecho positivo hasta nuestras sociedades, el derecho es la marco jurídico que los que ostentan el poder imponen a quienes se configuran como minoría.

Por otro lado, en la zona del mundo otra cultura propone un concepto de paz, la paz shalon o bienestar, asociado a la expresión "le-shalem alechim" que significa completar, retribuir, compensar, por eso una de las leyes más importantes de la tradición hebrea es el descanso del sábado como forma de retribución por el trabajo propio y el de los demás y el tiempo de dialogar con Dios. Esta propuesta tiene una connotación no solo interpersonal sino intrapersonal, yo y Dios. Deviene de la necesidad de establecer una sociedad que se aleja del esclavismo luego de escapar del cautiverio imperial, en la tradición hebrea, como en otras tradiciones religiosas se desarrolla un alto grado de machismo y clasismo que excluye de este estado de bien-estar a parte de la población, mientras busca cumplir con los criterios morales y religiosos de pureza y apariencia. La tradición judeo-cristiana hereda esta lógica, matizada por siglos de oscurantismos religiosa llega hasta nosotros preocupados por "estar en paz con Dios, para ir al cielo".

Al otro lado del mundo y desconectado civilicitoriamente, los pueblos andinos se proponen hasta los días de hoy, el buen vivir, tomado del sumak kawsay, una propuesta ética filosófica de establecer relaciones con los demás, con lo sobrenatural o las deidades y el mundo espiritual, así también con la naturaleza a quien se le considera un sujeto, en este caso la Madre. La propuesta es comúnmente compartida por otros pueblos de la región latinoamericana que antes de la llegada de los colonizadores compartían elemento culturales materiales e inmateriales, esta propuesta llega a no- 
sotros en primer lugar en la palabra y el ejemplo de los abuelos que son sin teoría enseñaron a conversar con las plantas o pensar que las montañas y la lluvia sienten, piensan, hacen o las relaciones de reciprocidad dentro de la comunidad. (Gudynas \& Acosta, 2011) El buen vivir tiene una seria de principios aplicables a la vida particular y concreta, saber tomar, saber comer, saber danzar directamente asociados con la felicidad colectiva.

En la tradición latinoamericana más próxima a nuestros pueblos, en los últimos siglos se entiende de la guerra un medio para construir la paz, "Y comprendió que la guerra era la paz del futuro" debido al sometimiento en el que se encontraban. Desde las guerras de independencia, como la liderada por Simón Bolívar, las guerras

\section{En la tradición latinoamericana más próx-} ima a nuestros pueblos, en los últimos siglos se entiende de la guerra un medio para construir la paz, "Y comprendió que la guerra era la paz del futuro" que constituyen lo que es la cultura de paz la Nicaragua de hoy.

Uno de las medidas más importantes es la liberación de 450 reos capturados durante los brotes de violencia del año 2018, acusados por delitos de terrorismo, incitación al odio, obstrucción de labor pública y destrucción de bienes públicos y privados entre otros muchos delitos.

Esta medida es sustentada en la ley de amnistía aprobada por el parlamento y es una medida que provocó reacciones de diversa índole, solo basta imaginar lo que sintieron y vivieron los familiares de las personas asesinadas torturadas al ver salir a aquellos que provocaron tanto daño, sin embargo y a pasar de esta reacción natural muchas de estas famili- de liberación y autodeterminación como la librada por el general Sandino, las guerras de revolución como la librada por Zapata, o por la defensa territorio como la de Fidel Castro en playa Jirón. Las venas abiertas de américa latina nos muestran esas muchas batallas y Nicaragua no es la excepción, aquí se han librado todas estas batallas en todas ha tocado empuñar un arma para asegurar la paz, la tradición revolucionaria latinoamericana es movida por el ejemplo de incontables guerrilleros, poetas, campesinos, sacerdotes, niños, mujeres, obreros, estudiantes, todos signados por la necesidad de construir la paz a las generaciones futuras.

\section{Elementos de la cultura de paz en Nicara- gua}

Nosotros herederos de estas y otras lógicas culturales tenemos el reto de construir una cultura de paz para nosotros, aquí y hoy, es decir, acoplada a nuestros tiempos, a nosotros y a nuestras circunstancias presentes, la reconstrucción de lo destruidos, el castigo para los infractores, la reconciliación familiar, entre otras son tareas para la Nicaragua de hoy.

En este sentido podemos enumerar algunos elementos as se pronunciaron a favor de una medida que aportará a recobrar la paz que tanto empezamos a valorar luego de aquel derroche de violencia e intolerancia.

Esta medida radical dejo al descubierto la imposibilidad y la incapacidad de negociar en busca de paz de una oposición aferrada a la violencia y al poder "superior" y sus suministros de dólares y evidenció la disposición policéfala que se sentaba y levantaba de la mesa como niño inquieto que aún decide que quiere. Esta capacidad para desnudar las verdaderas intenciones dentro y fuera de Nicaragua, aún a pesar de la maquinaria mediática, es central en la cultura de paz, las políticas de Estado claras, concisas y evidentes como la clave para evitar una nueva recaída en la mentira y la manipulación. Nicaragua cuenta con estado dispuesto a negociar, cumplir con sus acuerdos y dar respuesta política las provocaciones que buscan confrontación.

Durante los últimos meses el gobierno de Nicaragua ha liberado a un sinnúmero de reos comunes que bajo el régimen de convivencia familiar puede intentar rehacer sus vidas, las cuales estaban deshechas por incurrir en delitos comunes de menor envergadura, lo que implica la posibilidad de que un Estado renuncie a la cárcel como una forma de combatir el delito. 
Este modelo tiene sus antecedentes en el trabajo realizado por la policía durante muchos años en el combate a los grupos juveniles en situación de riesgo por programas de intervención comunitaria y educación, mucho más efectivos que los programas de mano dura y súper mano dura implementados en el Salvador para combatir a las maras.

Otro elemento para asegurar la paz y la tranquilidad de las familias nicaragüenses hoy por hoy es el trabajo efectivo de la policía nacional, policía nacida en el seno de la Revolución Popular Sandinista, cosa que le ha ganado el odio visceral de la oligarquía y de los grupos de clase media que se sienten ocupando wall Street. Durante el intento fallido de golpe de estado fueron asesinados 22 policías, según datos oficiales del tercer informe de la Comisión de la verdad, Justicia y Paz, publicado en febrero 2019 (Comisión de Verdad Justicia y Paz, 2019)

De estos 22 policías algunos fueron asesinados en enfrentamiento en las calles, otros en sus estaciones de policía, de donde fueron atacados por grupos armados, resultando asesinados, torturados y desaparecidos. En la medida en que la policía nacional recupero el control de las calles los asesinatos, destrucción de vienes públicos, incendios provocados en viviendas, saqueos a locales comerciales y tranques que impedían la libre movilización fueron desapareciendo.

La Nicaragua paralizada donde se le impedía al pueblo trabajador movilizarse o al comerciante atender en su negocio, quedo en el imaginario de algunos como un episodio épico, aplaudido por los sectores empresariales y oligárquicos que nunca les falto la comida y volaban a Washington o Miami mientras el pueblo no podía ir a sus trabajos. Hoy por hoy las familias regresan a los parques, los turistas nacionales y extranjeros visitan nuestros municipios, pero esa tranquilidad es debido al trabajo de un cuerpo que lejos de la perfección asegura las condiciones para continuar el desarrollo social y económico de las familias nicaragüenses. Otro importante espacio donde se asegura la paz para las familias es el trabajo en redes sociales, un verdadero campo de batalla de mentiras, verdad y posver- dad (Nuñez, 2018) donde buena parte de la población recurre lamentablemente a informarse y para donde mucho se dictan verdades. En Nicaragua abundan los ejemplos de noticias falsas y mentiras descabelladas que lo hacen viral, las redes sociales fueron usadas para provocar reacciones emocionales en base a estas noticias falsas o medias verdades, la manipulación de símbolos muy propias de los golpes blandos y las revoluciones de colores, poco a poco la población está aprendiendo a discernir lo que ventila en Facebook y twitter. También ha sido un proceso de aprendizaje para quienes defienden el proceso revolucionario en Nicaragua al usarlo como una herramienta que asegura la tranquilidad y campo de batalla que no hay que perder de vista.

Nicaragua está sentado precedente a nivel mundial con la conformación de comisiones de paz que para el mes de agosto del presente año ya existen 6 mil 706 en todo el país, estas comisiones están conformados por ciudadanos, lideres naturales de todos los signos religiosos y políticos, tiene como finalidad que en cada municipio del país se promueva la cultura de paz desde los propios actores y que se aporte la reconciliación de las familias y la comunidad luego de la profundas heridas dejadas por la confrontación y la división a raíz de los hechos de violencia vividos en el año 2018.

La identificación de víctimas de la violencia y la planificación de acciones de encuentro comunitario que aporte al proceso de duelo y sanación. Al frente de este esfuerzo se encuentra el diputado Carlos Emilia López, docente la maestría en Antropología y Liderazgo Social quien ha recorrido Nicaragua entera instalando las comisiones y dándole seguimiento a este trabajo, este esfuerzo está respaldado en términos políticos por la voluntad de un estado de concretizar la cultura de paz en instrumentos orgánicos que la gestionen.

La política de estado se extiende en todo el territorio y en todos los ámbitos de vida pública del país. En el departamento de antropología de la Universidad 
Nacional Autónoma de Nicaragua, Managua, UNAN - Managua estamos desarrollado un "diplomado en protagonismo Juvenil para Gestión Sociocultural y la cultura de paz" 30 jóvenes líderes de varios municipios se capacitan en herramientas y técnicas para el trabajo comunitario, estos jóvenes cuentan con una beca completa del Ministerio de la Juventud y desarrollan en sus comunidades de origen un trabajo de aplicación y multiplicación. El consejo Nacional de universidades desarrolla un programa que incluye a todas las universidades públicas del país en "universidades para la paz" que busca convertir a las casas de estudios superiores en recintos que promuevan y animen la cultura de paz entre la comunidades universitarias.

\section{Conclusión}

La cultura de paz, no se decreta, ni se impone, se construye, la construyen los pueblos en la búsqueda de su bienestar, en Nicaragua estamos en la búsque-

\section{Bibliografía}

Comisión de Verdad Justicia y Paz. (1 de septiembre de 2019). Comisión de Verdad Justicia y Paz. Obtenido de Comisión de Verdad Justicia y Paz: https://www.cvjp.org.ni/

Comisión de Verdad, Justica y Paz . (24 de mayo de 2019). Comisión de Verdad, Justicia y Paz. Obtenido de https://www.cvjp.org.ni/

Gramsci, A. (1967). La formación de los intelectuales. México: Grijalbo. da de la misma luego de vivir bajo el yugo del empobrecimiento neo-colonial, la construcción de un estado favor de los más pobres y un intento de golpe de estado. En este contexto histórico Nicaragua se encuentra construyendo su propia cultura de paz, con la voluntad política de un estado, el respaldo popular que esta tejiendo sus propios instrumentos cuídanos, que aunque no están libres de equivocaciones si están libre de elitismos.

Este ensayo pretende motivar pensar y repensar la cultura de paz desde nuestra experiencia, de cara a ir construyendo la cultura de paz desde nuestra experiencia histórica particular y los antecedentes filosóficos universales, que elementos del pasado de la humanidad acarremos con nosotros y cuales no son útiles. La construcción de la cultura de paz es la respuesta el golpe de estado, al germen del fascismo y del desarrollado clasismo que han practicado los grupos oligárquicos por muchos años y ensayan las clases medias recientemente por imitación.

Gudynas, E., \& Acosta, A. (2011). La renovación de la crítica al desarrollo y el buen vivir como alternativa. Utopía y Praxis Latinoamericana, 71-83.

Nuñez, R. R. (2018). Los efectos de la posverdad en la democracia. Revista de Derecho Político, 191-228.

Organización de las Naciones Unidas. (31 de julio de 1997). Hacia una cultura de Paz. NY: Naciones Unidas.

Soto, O. N. (2015). El Metabolismo del Mercado.

\section{Xavier Ernesto Rodríguez Corea}

Desde muy joven participa activamente en diversos movimientos sociales, especialmente Comunidades Eclesiales de Base (CEB) donde asume responsabilidades vinculadas con la formación desde la perspectiva de la Educación Popular. De allí que se especializa en el acompañamiento procesos de educación organización y comunicación en diversos espacios, especial-mente con jóvenes. Desarrolla diversas experticias de voluntariado y pasantías destacándose el trabajo con mujeres en situación de prostitución y explotación sexual comercial, tratamiento de adicciones y comunicación popular. Máster en Antropología y Liderazgo Social, actualmente desarrolla la docencia en la Universidad Nacional Autónoma de Nicaragua, Managua, en el Departamento de Antropología. 